\title{
DIRETRIZES PARA GERENCIAMENTO DOS REQUISITOS DO CLIENTE E AGREGAÇÃO DE VALOR AO PROCESSO DE PROJETO
}

Bruna Alessandra Gaffuri, José Carlos Rehme, Stéphanie Ferrari Teixeira.

Universidade Estadual de Londrina - UEL, mestrado em Metodologia de Projeto - Londrina - PR. E-mail: stephanie@ferrariarquitetura.com

\section{RESUMO}

A busca pela agregação de valor tem aumentado no setor da construção civil nas últimas décadas. No entanto, dificuldades como capturar os requisitos do cliente, controlar o fluxo de informações e otimizar as fases de desenvolvimento de projeto ainda impedem que o processo obtenha maior valor agregado. Este trabalho tem por objetivo propor um conjunto de padrões para o gerenciamento destas etapas. Para tal, foi desenvolvido um estudo de caso em um pequeno escritório de arquitetura em Arapongas - PR, através do mapeamento do processo de projeto. Com o levantamento das ações positivas e defasagens da atual gestão, os processos da microempresa foram modelados através de um software organizacional, e as informações obtidas, contrastadas com referenciais teóricos. Este estudo possibilitou um conjunto final de diretrizes para reduzir erros de gestão e de sequência de atividades a um nível mínimo.

Palavras-chave: Gestão de projetos; construção civil; agregação de valor; desenvolvimento de produto.

\section{GUIDELINES FOR MANAGING CUSTOMER REQUIREMENTS AND ADDING VALUE TO THE DESIGN PROCESS}

\begin{abstract}
The search for value generation has recently increased in the construction industry in the past decades. However, some difficulties in capturing end-customer requirements, controlling the flow of information, and optimizing project development phases prevent a product development process from receiving greater value aggregation. The present research aims to propose a set of standards for the management of these steps. In this way, a case study was developed in a small architecture office in Arapongas - PR, through the mapping of the project process. After a survey of the positive actions and lags of the current management the processes of the microenterprise were modeled through an organizational software and the information obtained was then contrasted by means of theoretical references. This study enabled a final set of guidelines to reduce management errors and sequence of activities to a minimum.
\end{abstract}

Key-words: Project management; civil engineering; adding value; product development.

\section{INTRODUÇÃO}

O processo de desenvolvimento de projeto dentro da construção civil tem impacto direto nos custos, na qualidade do produto final, e no tempo de execução de um empreendimento. Por ser um processo de tomada de decisões e de definições, deveria ser observado com mais precisão e assertividade. Entretanto, observamse lacunas no gerenciamento inadequado desse processo: análise vaga dos requisitos do cliente $\mathrm{e}$ participação mínima do mesmo; centralização das informações relacionadas a estes requisitos e ineficiente comunicação entre os intervenientes; indefinição de responsabilidades e/ou ausência de coordenação; ocorrência de erros e retrabalhos em projetos; deficiência do planejamento e alocação de recursos; perda de informações; excesso de mudanças e ausência de atribuição de prazos, dentre outros.

Uma questão recorrente é a de que, quando não há uma comunicação clara entre os envolvidos e quando as informações não são compartilhadas de forma efetiva, gera-se retrabalho em alguma etapa posterior do processo. Ou seja, a revisão somada a correção desta falha demanda o tempo que deveria ser empregado nalguma outra etapa. Por outro lado, quanto menor o tempo de processo, maior é o 
valor a ser reconhecido em determinado serviço ou função. E sendo assim, quando as etapas que geram perdas são reduzidas ou eliminadas, o produto final tem maior valor agregado.

Com o crescente desenvolvimento do mercado da construção civil urge a necessidade de um processo de desenvolvimento de produto (PDP) mais eficiente e lucrativo. Cada vez mais clientes buscam, além de um projeto bem resolvido e desenvolvido com a identidade do seu comprador, um que possa ser realizado dentro de um tempo limite e, preferencialmente, com alto grau de assertividade entre os recursos oferecidos e aqueles de fato aplicados. Assim, cada vez mais linhas de pesquisa seguem na área de gestão do processo de desenvolvimento de projeto. O objetivo deste estudo foi buscar uma maior eficiência nas etapas desse desenvolvimento, e maior agregação de valor a todo o processo.

\section{FUNDAMENTAÇÃO TEÓRICA}

Segundo Miron (2003), a compreensão de valor é a busca de desejo e satisfação; seu significado muda de uma pessoa a outra e para a própria pessoa de um momento para outro, dependendo do contexto. A percepção de valor está na relação entre os benefícios percebidos pelos sacrifícios percebidos, onde o benefício é percebido pelo desempenho do produto para que o cliente alcance seus objetivos. Sua representatividade está diretamente relacionada à satisfação das necessidades e inversamente ao custo.

Além de considerar uma definição rigorosa de projeto, design e construção enxutos, já sugeridos por Ballard (2008), os critérios de design deveriam ser estipulados com base nos valores e estes, por sua vez, com base nos propósitos de projeto.

Falhas no processo de desenvolvimento de projeto são passíveis de solução a partir de um direcionamento focado em agregar valor e evitar perdas. Autores como Koskela (2001) propõem algumas teorias e métodos a respeito desta questão. Em seus estudos, ele defende a teoria TFV - Transformação de inputs e outputs, Fluxo de informações através do tempo e espaço, e Geração de Valor para o cliente. Estes três pontos de vista devem ser desenvolvidos de forma que se completem, sem competir entre si. O primeiro passo para isto seria a integração mais efetiva entre projeto e engenharia, do começo do projeto ao fim da construção. Assim, as decisões e detalhes projetados em conjunto seriam mais eficientes; resultando em maior assertividade e eficácia na construção.

A teoria TFV demonstra que atualmente a construção convencional faz uso apenas do conceito de transformação, ou seja, direcionar uma tarefa apenas ao seu início e conclusão, sem considerar o processo de desenvolvimento como um todo. Isso significa que outros dois fatores importantes (tempo e cliente) são esquecidos ou negligenciados.

Além de considerar clientes como membros ativos da equipe deve-se levar em conta a relação direta entre o sucesso do projeto e o modo como os requisitos do cliente são comunicados a equipe que irá desenvolve-lo. Sendo assim, Miron (2003) sugere a seguinte diretriz, dividida em três categorias: Identificação dos requisitos (1); Controle do fluxo de elaboração (2); e Avaliação do valor e armazenamento das informações (3).

De acordo com Ballard (2008), podemos ainda considerar na etapa de definição de projeto o alinhamento das seguintes variáveis:

Ends: compreender o propósito do cliente para determinar quais características do produto são valorizadas e quais serão tidas como estratégia.

Means: compreender como o produto será utilizado antes que ele seja elaborado.

Constraints: assimilar as interferências diretas nos interesses do cliente e no que representa valor para as partes envolvidas.

Com base neste referencial teórico, considera-se ainda as etapas estratégicas de Business Planning, Plan Validation, Target Costing e Design Development.

\section{MÉTODO}

$O$ estudo de caso foi realizado em um escritório de pequeno porte em Arapongas - PR, com atuação principal nas áreas de projeto arquitetônico e de interiores para obras residenciais. A fim de identificar o PDP, elaborouse um protocolo de mapeamento de projeto e um questionário de coleta de dados. Estas informações puderam ser distribuídas num diagrama criado no software Bizagi, através do qual foi possível visualizar todo o processo (a participação e as responsabilidades de cada envolvido, a complexidade do processo e o tempo despendido em cada etapa). Ao longo do plano bidimensional gerado foram adotadas simbologias a fim de apontar pausas, tomadas de 
decisão, retrabalhos, e pontuados aspectos positivos, observações reconhecidas como oportunidades de melhoria ou lacunas na gestão ao longo do processo.

Sobretudo, o presente trabalho aborda o conceito de valor pelos olhares de Miron (2003), as diretrizes para agregação de valor sugeridas por Ballard (2008), e a teoria TFV (Transformation, Flow and Value) proposta por Koskela (2001) sobre agregação de valor e solução de deficiências no PDP. Com base neste referencial teórico, as informações obtidas no case foram por fim comparadas a abordagens destes autores em questões semelhantes, e isto veio complementar o conjunto final de diretrizes para melhorias operacionais entregue ao escritório.

\section{RESULTADOS}

Segundo o modelo apresentado, apenas os arquitetos proprietários do escritório participam das etapas de reuniões com clientes e tomadas de decisão, e somente eles têm contato com os engenheiros de projetos complementares. Assim, a equipe de desenhos tem que se inteirar de todas as informações obtidas. Enquanto isto, inúmeras revisões e retrabalhos passam por um mesmo processo.

Figura 1. Trecho de um plano bidimensional com ênfase nas atividades dos arquitetos sócios proprietários.

Fonte: Autores.

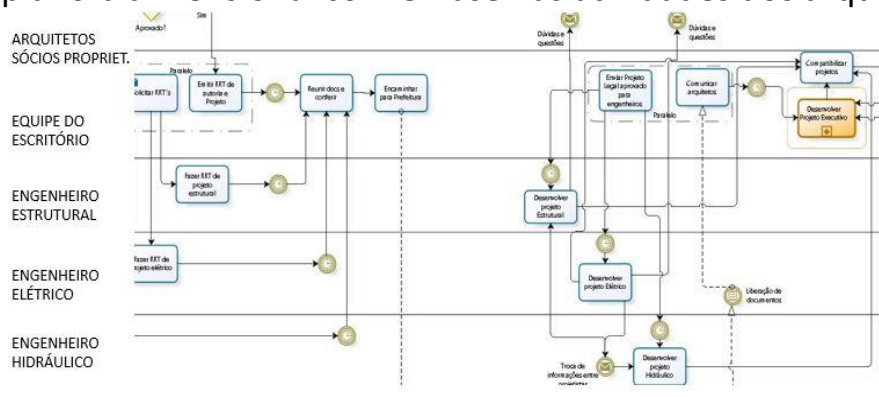

Em todo início de um processo de projeto é necessário que a equipe do escritório encarregada de tais fases deva buscar novamente as informações e entender todas as decisões tomadas e as possíveis alterações realizadas.

Figura 2. Trecho de um plano bidimensional com ênfase nas atividades da equipe interna.

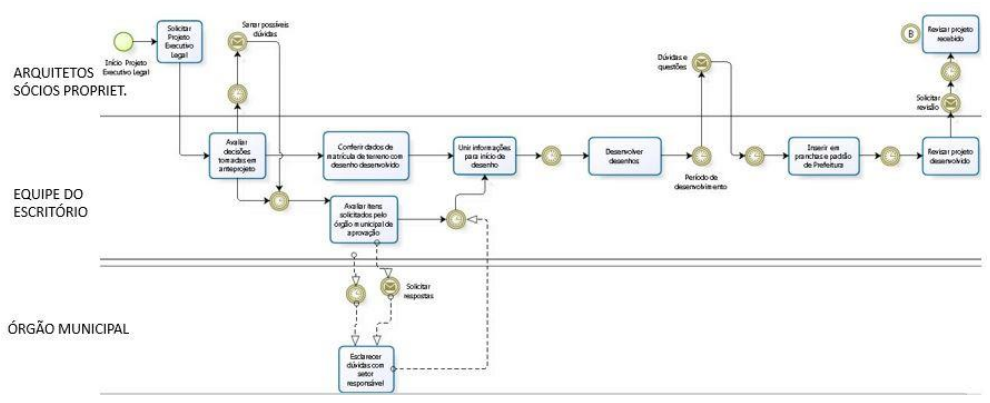

Fonte: Autores.

É possível visualizar no modelo Bizagi que o cliente aparece apenas no início do processo ou durante alguma decisão muito específica; sem ser consultado durante o desenvolvimento das demais etapas; o que pode gerar desentendimentos que só serão percebidos na fase de execução da obra. 
Figura 3. Trecho de um plano bidimensional com ênfase na participação limitada do cliente.

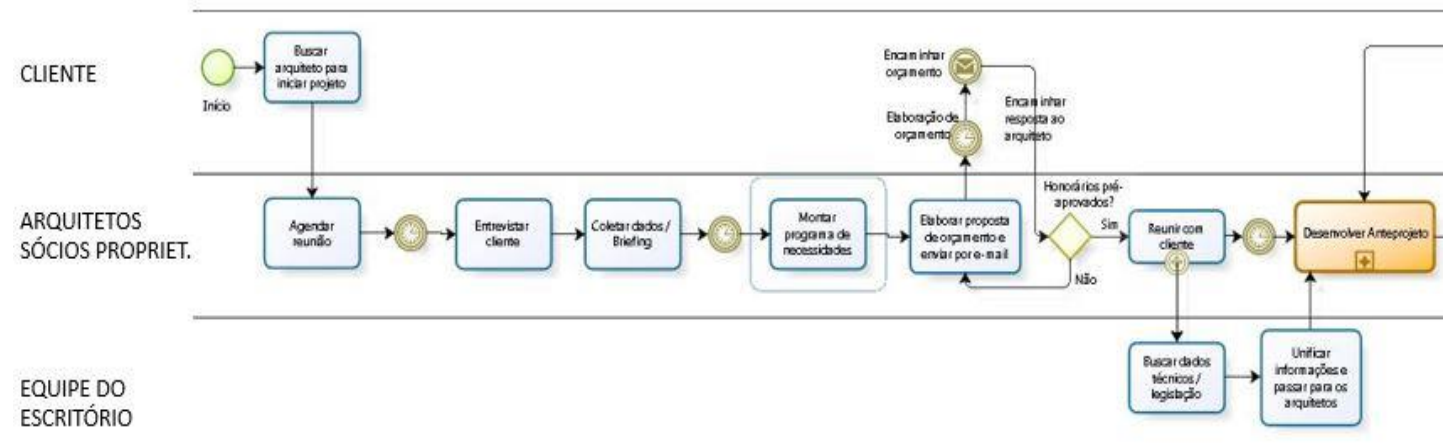

Fonte: Autores.

Todas estas questões geram outra situação agravante dentro do escritório: a espera. Todos os processos passam por inúmeras esperas e são pausados várias vezes até a sua conclusão.
Contribuindo para a revisão dos procedimentos de elaboração dos projetos, o quadro 1 apresenta uma correlação entre os elementos e a frequência em que aparecem durante o desenvolvimento do projeto.

Quadro 1. Representatividade dos elementos em relação à frequência que aparecem no processo de desenvolvimento de projeto.

\begin{tabular}{|l|l|l|}
\hline Elemento & Frequência & $\begin{array}{l}\text { Representatividade do } \\
\text { elemento }\end{array}$ \\
\hline Tarefas & 58 & $51,7 \%$ \\
\hline Tomadas de decisão & 8 & $7,1 \%$ \\
\hline Esperas ou enviar & 38 & $33,9 \%$ \\
\hline $\begin{array}{l}\text { Buscar } \\
\text { informações }\end{array}$ & $7,1 \%$ \\
\hline TOTAL & 112 & $100 \%$ \\
\hline
\end{tabular}

Fonte: Autores.

Logo, a primeira contribuição do estudo passa por definir estratégias de maior envolvimento do cliente nas diversas etapas de execução do projeto, para que possíveis incoerências nos itens do projeto, possam ser evitadas; analisando-as e revisando-as, em tempo de evitar erros, que repercutem em custos e atrasos. Estas inserções podem ser definidas no momento da contratação do serviço, definindo em cronograma as possíveis etapas de entregas e validações pelo cliente.

A segunda grande contribuição reside na maior socialização das informações do projeto para com a equipe desenvolvedora. Esta implica também em definir etapas no cronograma de projeto e convocar toda a equipe a participar, pois sem a devida intercomunicação, pode gerar ações indesejadas na sequência do projeto.

A terceira contribuição estaria na eliminação dos tempos de espera nas diversas fases do projeto, passando pela identificação de onde elas ocorrem e pela implementação de ações para reduzi-las ou eliminá-las.

E concluindo, a última consideração, decorrente das anteriores, consiste no registro dos pontos discutidos em cada etapa; um prontuário para cada projeto; configurados num banco de dados ao longo do tempo e da sequência de projetos diversos já realizados (medidas, padrões de acabamento, dúvidas, entre outros), e utilizados como referência para a execução de novos projetos, de categoria semelhante.

\section{DISCUSSÕES}

Durante a análise da sequência de atividades do escritório, o que primeiramente chamou a atenção foram as inúmeras vezes em que uma mesma etapa de projeto passou por verificações. Uma vez concluída certa etapa de desenvolvimento pela equipe interna, a mesma passa pela revisão de um dos arquitetos. A partir disto, qualquer informação incoerente faz com 
que todo o projeto retorne a fase inicial. A equipe depara-se, portanto, com situações de perda bastante marcantes: primeiramente, a revisão apresenta-se como o próprio retrabalho. E em seguida, a correção de projeto gera um novo atraso em seu andamento.

As considerações extraídas contribuem na eliminação de revisões, e assim, facilita-se a integração das equipes de projeto, estimula-se a comunicação, a responsabilidade e autoestima nos diversos cargos, ganha-se tempo útil e possibilidade de dedicação a mais projetos. E ainda, a aplicação dos seguintes padrões pode ser colocada em prática ou revista, tais como: nomenclatura, protocolos de envio e recebimento, e controle das versões de arquivos enviados à obra, diretrizes para produção e apresentação de desenhos, organização das sequências de projeto, etc.

Estas considerações permitem então, que o escritório seja remodelado e seu processo ganhe maior valor perante o cliente. Utiliza-las de modo isolado não é o suficiente, pois se faz necessária a ação conjunta para reestruturar o processo.

\section{CONCLUSÕES}

A introdução à uma sistemática para coleta de dados e gerenciamento dos requisitos do cliente, juntamente à aplicação de ações de melhoria para apoiar as tomadas de decisão ao longo do desenvolvimento do produto, implica em uma produção integrada mais eficiente, colabora na agregação de valor no processo de desenvolvimento e entrega do produto. Negligenciar esta sistemática ou mesmo as ações de melhoria, acarreta um grande impacto no tempo de desenvolvimento de projeto e na capacidade de aumentar o número de atividades ou possíveis projetos a serem desenvolvidos pelo escritório- num determinado período.

Algumas das diretrizes extraídas podem ser estendidas a outras tipologias de escritórios de arquitetura, engenharia e design. Ou ainda, utilizadas como modelo para incentivo organizacional de outras empresas. A aplicação destas ações poderá contribuir para um maior desempenho do processo de projeto e potencializar a agregação de valor ao produto a ser gerado por cada escritório ou empresa.

Como principais contribuições do trabalho, destacam-se a ênfase na necessidade de se mapear o processo de projeto, de gestão sobre os requisitos do cliente desde as fases iniciais de concepção do projeto, e o método proposto.

\section{REFERÊNCIAS}

BALLARD, G.. The Lean Project Delivery System: An Update. Lean Construction Journal, v. 2008, p. 1-19, 2008. Disponível em: $<$ https://www.leanconstruction.org/media/librar y/id53/The_Lean_Project_Delivery_System_An_ Update.pdf>. Acesso em: 7 nov. 2017.

BRITO, A. M. do A.. Diretrizes e padrões para produção de desenhos e gestão do fluxo de informações no processo de projeto utilizando recursos computacionais. 2001. Dissertação (Mestrado em Engenharia) - Universidade Federal do Rio Grande do Sul. Porto Alegre, 2001. Disponível em: http://www.lume.ufrgs.br/bitstream/handle/101 83/4029/000396140. pdf?sequence $=1$. Acesso em: 15 Out. 2017.

KLEINSMANN, M.; BUIJS, J.; VALKENBURG, R. Understanding the complexity of knowledge integration in collaborative new product development teams: A case study. Journal of Engineering and Technology Management, v. 27, n. 1/2, p. 20, mar./jun., 2010. Disponível em: <http://www.sciencedirect.com.ez78.periodicos. capes.gov.br/science/article/pii/S0923474810000 044?via\%3Dihub>. Acesso em: 7 Nov. 2017.

KOSKELA, L.; HUOVILA, P.; LEINONEN, J. Design Management in Building Construction: from theory to practice. Journal of Construction Research, v. 3, n. 1, p. 1-16, 2002. Disponível em:

<https://www.researchgate.net/publication/285 78920_Design_management_in_building_constru ction_From_theory_to_practice $>$. Acesso em: 7 Nov. 2017.

MIRON, L. I. G.; FORMOSO, C. T. Client requirement management in building projects. Disponível em: <http://www.academia.edu/10807062/CLIENT_R EQUIREMENT_MANAGEMENT_IN_BUILDING_PR OJECTS>. Acesso em: 7 Nov. 2017.

MIRON, L. I. G. Proposta de Diretrizes para o Gerenciamento dos Requisitos do Cliente em Empreendimentos da Construção. 2002. Dissertação (Mestrado em Engenharia) Universidade Federal do Rio Grande do Sul. Porto 
Alegre, 2002. Disponível em:

$<$ http://www.lume.ufrgs.br/bitstream/handle/10

183/1828/000359021.pdf?sequence=1> . Acesso

em: 15 Out. 2017.

Recebido para publicação em 25/03/2018

Aceito em 18/05/2018 